\title{
Honey Bees in the Tropics Show Winter Bee-Like Longevity in Response to Seasonal Dearth and Brood Reduction
}

\author{
Stephanie Feliciano-Cardona ${ }^{1 * t}$, Mehmet Ali Döke ${ }^{1 * t}$, Janpierre Aleman', \\ Jose Luis Agosto-Rivera', Christina M. Grozinger ${ }^{2}$ and Tugrul Giray ${ }^{1}$ \\ ${ }^{1}$ Department of Biology, University of Puerto Rico, San Juan, Puerto Rico, ${ }^{2}$ Department of Entomology, Center for Pollinator \\ Research, Huck Institutes of the Life Sciences, Pennsylvania State University, University Park, PA, United States
}

\section{OPEN ACCESS}

Edited by:

Isabel Marques,

University of Lisbon, Portugal

Reviewed by:

Ethel M. Villalobos,

University of Hawai'i at Mānoa,

United States

Panuwan Chantawannakul,

Chiang Mai University, Thailand

*Correspondence:

Stephanie Feliciano-Cardona

stephanie.feliciano2@upr.edu

Mehmet Ali Döke

malidoke@gmail.com

tThese authors have contributed equally to this work and share first

authorship

Specialty section:

This article was submitted to Behavioral and Evolutionary Ecology,

a section of the journal

Frontiers in Ecology and Evolution

Received: 24 June 2020 Accepted: 16 September 2020 Published: 16 October 2020

Citation:

Feliciano-Cardona S, Döke MA Aleman J, Agosto-Rivera JL, Grozinger CM and Giray T (2020) Honey Bees in the Tropics Show

Winter Bee-Like Longevity in Response to Seasonal Dearth and Brood Reduction.

Front. Ecol. Evol. 8:571094. doi: 10.3389/fevo.2020.571094
Upon their first introduction to Americas in 1956, African honey bees (Apis mellifera scutellata) hybridized with the previously introduced and already established European honey bees (EHBs). The resulting Africanized honey bees (AHBs) have spread through the continental tropics of the Western Hemisphere. The expansion of AHB has been constrained in temperate climates generally thought to be because of a lack of key adaptations required for successful overwintering. A drastic increase in longevity during broodless periods is crucial to colony survival. In the temperate regions, honey bee colonies become broodless in winter. While tropical regions do not experience winters as temperate zones do, seasonal changes in the abundance of floral resources cause variation in brood levels throughout the year. Here we use an island population of AHB in Puerto Rico (gAHB) to test the capacity of tropical-adapted honey bees to alter their longevity in different seasons, as well as under brood manipulation. We found that worker longevity in the gAHB colonies increases in the wet season (maximum longevity ca. 88 days vs. 56 days) in response to dearth of floral resources. A more pronounced increase in longevity was observed in response to manipulative reduction of the amount of open brood (maximum longevity 154 days). In addition, long lived gAHB demonstrated the signature winter bee-like hypopharyngeal gland size (average acini diameter $100.8 \pm 6.2 \mu \mathrm{m}$ at 65 and 70 days of age, $N=26$ ), intermediate between forager (88.7 $\pm 5.9 \mu \mathrm{m}, N=24)$ and nurse $(129.5 \pm 8.1 \mu \mathrm{m}, N=24)$ gland size. We showed that gAHBs do not lack the adaptation to alter their longevity seasonally, though the magnitude of changes is less intense than those observed in EHBs during temperate winters. This suggests that increased longevity in response to limited capacity to rear brood is a shared character of Africanized and European honey bees.

Keywords: honey bees, life-span, brood, tropics, seasonal dearth

\section{INTRODUCTION}

Present honey bee distribution spans every continent except Antarctica. However, the species originated in lower latitudes and is unlikely to have experienced temperate climates until major expansions into higher latitudes (Cridland et al., 2017). Temperate winters are marked by low temperatures and a lack of floral resources. While extreme low temperatures are not a part of 
the tropical climate, seasonal dwindling of floral resources is a shared feature between the two regions (Little et al., 1977). Honey bees differ from virtually all other insects in their overwintering strategy. Rather than undergoing dormancy, honey bees survive the winter in a metabolically and physically active state using the food stored earlier in spring and summer and generating heat inside the thermoregulatory cluster (Stabentheiner et al., 2003, reviewed in Döke et al., 2015). Beginning at the end of summer and early fall, worker bees with increased longevity (up to four times that of spring months) gradually appear in the colonies (Fluri et al., 1982). By mid-fall, long-lived workers constitute the majority of the hive population (Fukuda and Sekiguchi, 1966; Mattila et al., 2001). In addition to the greater longevity, winter bees are different from their sisters that were produced in spring in their hypopharyngeal gland size, juvenile hormone and vitellogenin levels, and hemolymph protein content (Fluri et al., 1982). As part of this strategy, colonies reduce brood production during the winter months which creates a need for the existing workers (produced in fall) to sustain the colony population into the next spring (McLellan, 1978). There are two possible evolutionary histories for the winter-adaptive traits: (1) There has been selection as populations radiated into the temperate climates, favoring new variants with winter-adaptive traits (i.e., adaptive evolution) or (2) existing traits utilized to cope with environmental stressors in the tropics were coopted (i.e., exaptation). Examining flexible longevity in the introduced tropical honey bee populations in Americas can provide evidence in support of one or both scenarios.

The AHB populations in the Western Hemisphere were originally introduced in Brazil in 1956 and have subsequently hybridized with EHB previously brought over from Europe in the 1600s (Pinto et al., 2007; Rivera-Marchand et al., 2008; Kono et al., 2015; Lin et al., 2018). In an earlier study, it is reported that AHB in Venezuela demonstrated change in brood production over the tropical seasonal cycles suggesting tropical bees exhibit some degree of seasonal response (Winston et al., 2016). Here, we examined another tropical population of honey bees on the island of Puerto Rico (PR). The bees in PR are derived from Africanized honey bees, likely introduced from Texas ca. 1994 (Galindo-Cardona et al., 2013; Acevedo et al., 2019) and named gentle Africanized honey bees (gAHB) given a secondary, drastic reduction of colony defensive response (Rivera-Marchand et al., 2012; Avalos et al., 2017). In this study, we tested the capacity of gAHB to alter their longevity in accordance with different seasons and colony reproductive states in observational and experimental studies.

In PR, bees do not experience the same degree of cold stress that bees in temperate regions experience. Ambient temperatures in $\mathrm{PR}$ oscillate minimally both daily (maximum $8^{\circ} \mathrm{C}$ change within a day) and seasonally (maximum $3.5^{\circ} \mathrm{C}$ change between monthly average temperatures) ${ }^{1}$. However, despite relatively stable and warmer temperatures, PR has strong seasonal differences based on flower phenology (Figure 1). These differences in flower phenology create a similar stressor to temperate regions where forage resources are abundant in

${ }^{1}$ https://www.weather.gov/sju/climo_pr_usvi_normals one part of the year and heavily reduced in the other. The decoupling of resource availability and cold stress, combined with the evolutionary history of the honey bees on the Island, makes PR an excellent location to test whether increased worker longevity is a winter-specific adaptation or a more generalized response to seasonal dearth.

While long-lived bees occur naturally in fall, their production can also be induced in summer by confining the queen in a cage inside the hive and thus preventing brood production (Maurizio, 1950; Fukuda and Sekiguchi, 1966; Fluri et al., 1982). In manipulative studies, the reduction in brood or open brood (i.e., larvae less than 5 days of age that require feeding by nurse bees) results in increased longevity (Maurizio, 1950, 1954; Eishchen et al., 1982; Omholt, 1988; Harbo, 1993; Amdam et al., 2009; Smedal et al., 2009; Döke et al., 2015). However, the studies demonstrating that limiting brood production generated workers displaying winter physiology were conducted with colonies from populations of EHB known to overwinter successfully in the temperate regions. Changes in longevity of tropical bees, either seasonally or induced by brood manipulations, have not been studied before.

In this study, we followed paint marked cohorts of worker honey bees within the colonies in our field station in PR to establish a baseline for the seasonal change in longevity in a tropical setting. We next tested the effect of experimentally induced reduction in brood availability, and its effect on traits generally considered winter-specific. We hypothesize that the presence of changes in winter-specific traits in a population that has been historically exempt from the burden of overwintering would suggest these are general adaptations induced by environmental stressors. Alternately, if no change is observed in gAHB, then adaptations must have evolved during the radiation to temperate regions and are maintained by selective pressure specific to winter conditions.

\section{MATERIALS AND METHODS}

\section{Sources of Bees}

All experimental gAHB colonies were maintained according standard techniques (Kevan, 2007) in the apiary located at the Agricultural Experimental Station of the University of PR Mayaguez in Gurabo, PR (N 18.257294, W 65.987871).

\section{Seasonal Change in Worker Longevity}

In October, 2018, we set up two healthy colonies, each with 10 frames of worker bees ( $\sim 20 \mathrm{k}$ bees), pollen, honey, capped and uncapped brood and a mated, laying queen. One of the colonies was selected as a donor for all the emerging adult bees to be marked and introduced into both colonies. Using a single source for the introduced workers provides a uniform genetic background for the subjects and thus limiting simplifying the experimental design compared to having two separate genetic backgrounds included as an independent variable. In the beginning of October, frames of capped brood ready to emerge were selected from each colony and placed in an incubator at $34^{\circ} \mathrm{C}$ with $60 \%$ relative humidity for approximately $24 \mathrm{~h}$. One 

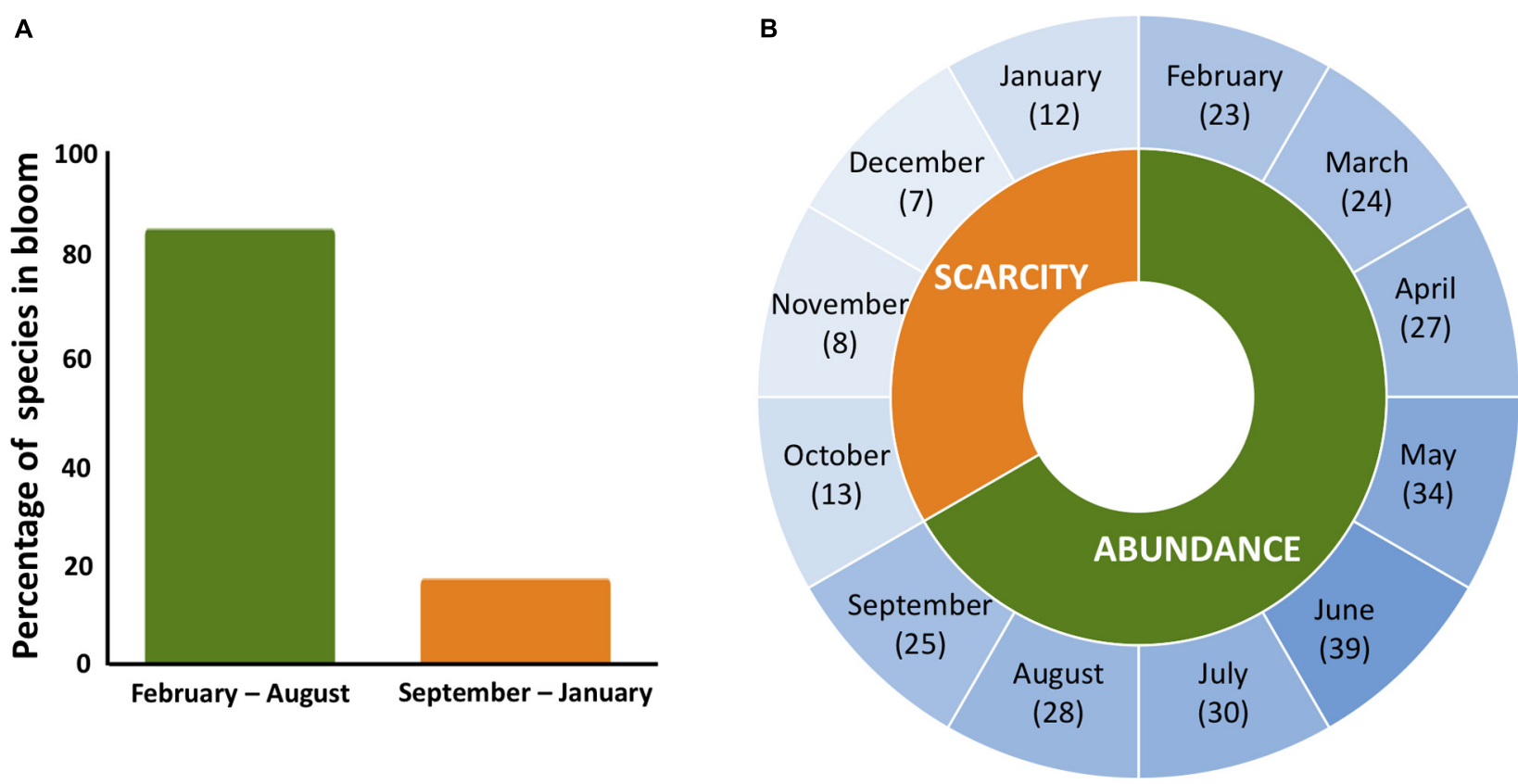

FIGURE 1 | Flower phenology in PR. (A) Blooming rate of the 61 trees in PR that are regularly visited by the honey bees throughout the year. (B) In PR, the number of species in bloom is highest in June and lowest in December. For 4 months (October-January) floral resources are scarce with an average of ten species in bloom compared to the other 8 months (February-September) when, on average, 29 species are flowering. Data from Little et al. (1977).

single cohort of 1,000 1-day old bees were paint marked on the thorax (Testors Paint, Rockford, IL) and 500 one-day-old bees were released into each colony. The number of marked survivors in each colony were recorded every 12 days until no more marked bees were observed in November. The counts were made by observing marked workers on frames and inner surfaces of the hive body early in the morning to avoid miscounting due to increased flight activity later in the day (Mattila et al., 2001).

Another set of longevity data collected from colonies set up in March 2018 is used for comparing worker longevity between seasons (see below for details). We used the data from control colonies which are unmanipulated (i.e., have mated, laying queens instead of caged queens). These were also the control colonies in the experiment testing the effect of elimination of open brood on worker longevity. Please note that we decided to report our results out of chronological order and rather based on a logical order for more effectively communicating the findings from separate and their relation to each other.

In October 2018, average temperature for the month was $27.7^{\circ} \mathrm{C}$ with a high of $32.8^{\circ} \mathrm{C}$ and low of $23.9^{\circ} \mathrm{C}$; whereas, average temperature in March 2018 was $25.9^{\circ} \mathrm{C}$ with a high of $32.2^{\circ} \mathrm{C}$ and a low of $21.1^{\circ} \mathrm{C}^{2}$.

\section{Worker Longevity in Colonies With Curtailed Open Brood}

In mid-March, 2018, 10 nucleus colonies each with 5 deep frames were established from existing full-size colonies in our research apiary. Control colonies $(N=5)$ composed of 1 empty frame

${ }^{2}$ https://w2.weather.gov/climate/index.php?wfo=sju with foundation, 1 frame of honey, 1 frame of pollen, and 2 frames of open brood and treatment colonies $(N=5)$ composed of 1 empty frame with foundation, 1 frame of honey, 1 frame of pollen, and 2 frames of capped brood for treatment colonies (see Figure 2, Step 1). Control colonies had laying queens while in treatment colonies, the queen was separated from workers via a push-cage (Maurizio, 1954; Fluri et al., 1982). The pushcage for queen confinement was made using wire mesh as in Le Conte et al. (2001) and this separation of the worker and queen breaks the brood production as the small number of eggs laid by the queen cannot be cared for by nurse bees. At the point of establishment all five frames in each colony were fully covered in worker bees bringing the colony population to an estimated 15000 workers (Jeffree, 1951). Upon establishment of the nucleus colonies, frames of capped brood that are ready to emerge were collected from several full-size colonies in the same apiary and placed in an incubator at $34^{\circ} \mathrm{C}$ with $60 \%$ relative humidity for approximately $24 \mathrm{~h}$ (see Figure 2, Step 2). Over the next 2 days, 4000 1-day-old bees were paint-marked on the thorax (Testors Paint, Rockford, IL) and then 400 bees were introduced to each of 10 colonies to establish single cohort of bees of known age in each colony (Mattila et al., 2001, See Figure 2, Step 3). The treatment colonies were monitored regularly to ensure the queens were alive in the cage (Smedal et al., 2009). Colonies which became queenless (4 out of 10) were removed from the study and not included in the analyses even when data was collected prior to their removal. Periodical survival checks were made every 2 weeks from April until there were no marked survivors in the colonies (see Figure 2, Step 4). The counts were made early in the morning to avoid 
Step 1: Form nucleus colonies with free and caged queens

Control colonies

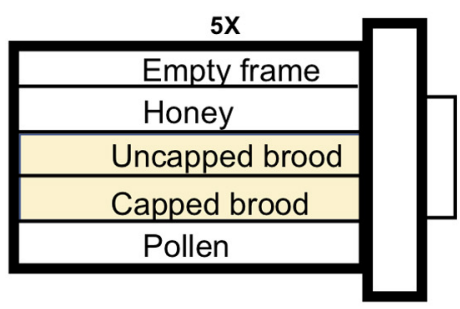

Treatment colonies

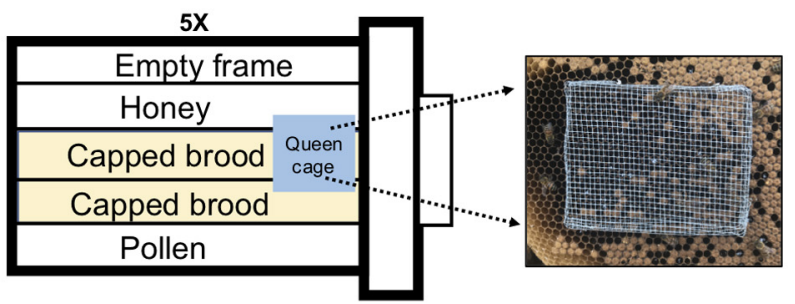

Step 2: Collect capped brood frame ready to emerge and incubate for $24 \mathrm{hr}$.

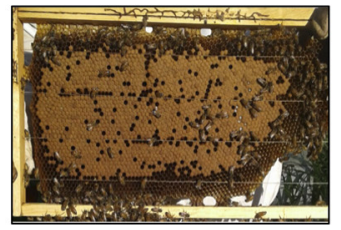

Step 3: Next day paintmark the 1 day-old bees

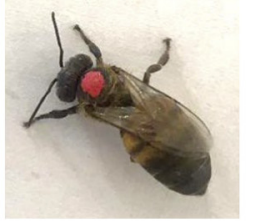

Step 4: Perform the survival check of paint-marked bees every 2 weeks

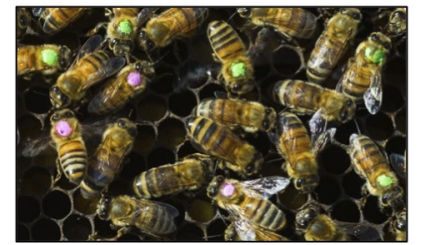

FIGURE 2 | Overview of the overall strategy, materials, and methods for worker life-span with reduced brood rearing. Control Colonies (CC) were set up to approximate the typical conditions of a colony in spring. Although no uncapped brood was present in Treatment Colonies (TC), overall amount of brood was equalized between the CC and TC by introducing capped brood from CC to TC as needed.

miscounting due to increased flight activity later in the day (Mattila et al., 2001).

\section{Sample Collection}

Worker honey bees were collected from both control and treatment (curtailed brood) colonies that were established in March 2018. Twelve days after the introduction of marked worker bees, nurses were collected via behavioral observations of brood care, while the bees were feeding the young brood (as in Vannette et al., 2015). Twenty-one days after the introduction of marked worker bees, foragers were collected by temporarily blocking the hive entrance using a wire mesh and individually picking the workers coming back from foraging flights with a visible load of pollen (as in Giray et al., 1999; Vannette et al., 2015). Later samples were collected from inside the nucleus colonies merely based on marked worker age (45, 65, and 70 days old). All samples were collected into liquid nitrogen in the field, transported to the laboratory on dry ice in an insulated box, and kept at $-80^{\circ} \mathrm{C}$ until processing (Grozinger et al., 2003).

\section{Dissections and Hypopharyngeal Gland Measurements}

Four bees per colony (age and treatment) were dissected. Frozen samples were kept on dry ice throughout their handling and the hypopharyngeal gland (HPG) was removed under a dissection microscope (Nikon C-LEDS, produced Nikon Instruments Inc., NY, United States). Dissected HPGs were kept in RNAlater ICE Frozen Tissue Transition Solution (Thermo Fisher Scientific, MA, United States) until measurement of the acini diameter as an estimate of the HPG size (Renzi et al., 2016). The diameter of one acinus per sample was digitally measured in $\mu \mathrm{m}$ (Nikon Eclipse
E200 microscope connected to a Nikon DS-Fi2 camera, Nikon Instruments Inc., NY, United States), then the mean acini size was calculated for each group. While it is common practice to use multiple acini measurements from each individual, the coefficient of variation within individual was small enough (0.09-0.21) to use single acinus data per worker with confidence to compare groups of workers (Shechtman, 2013).

\section{Statistical Analyses}

Kaplan-Meier Survival Analysis (Goel et al., 2009) was employed to compare the longevity of both cohorts of worker bees from different times in the year and cohorts from the manipulated versus control colonies. ANOVA was used to compare the acini size of worker bees of differing age that were collected from the experimental colonies. All statistical analyses were completed using JMP (JMP ${ }^{\circledR}$, Version 14. SAS Institute Inc., Cary, NC, 1989-2019) and graphs were plotted using Prism (GraphPad Prism version 6.00 for Mac OS X, GraphPad Software, La Jolla, CA, United States). Additionally, Microsoft ${ }^{\circledR}$ PowerPoint ${ }^{\circledR}$ 2016 and an open access vector graphics software, INKSCAPE (Version 0.92) were used in image preparation.

\section{RESULTS}

\section{Seasonal Change in Worker Longevity}

Mean and standard deviation of longevity for worker bees in October cohort (1000 individuals from 2 colonies) was $26.8 \pm 22.1$ days, significantly longer than the $23.6 \pm 12.9$ days for the March cohort (2,000 individuals from 5 colonies) (KaplanMeier Survival Analysis, Log-Rank $p<<0.05)$. None of the 
workers introduced to the colonies in March survived beyond 56 days while workers introduced in October had survivors up to 88 days (Figure 3). Note that the data represented as "March cohort" is the same as the data for control colonies (i.e., with mated, laying queen) in the manipulative experiment where half of the colonies had curtailed open brood. We chose to use this data for both comparisons because control colonies were nonmanipulated and thus constitute a good representation of natural longevity for the season in which they were observed.

\section{Worker Longevity in Colonies With Curtailed Brood Production}

Maximum longevity in the treatment colonies was 154 days, while the bees of control colonies survived up to 56 days. Mean and standard deviation of longevity for worker bees released to colonies without open brood was $35.2 \pm 24.5$ days, significantly longer than the $23.6 \pm 12.9$ days for the workers in control colonies (Kaplan-Meier Survival Analysis Log-Rank $p<<0.05$, Figure 4). We also explored the effect of colony identity on longevity via comparing colonies within control and treatment

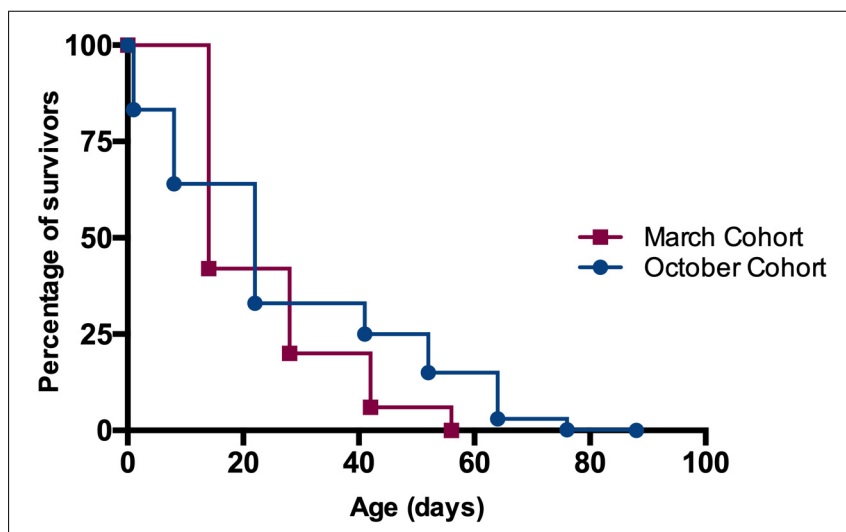

FIGURE 3 | Monitoring the longevity of worker bees in different months in PR. Cohort of 1-day old bees introduced in October had significantly greater longevity than the ones introduced in March ( $26.8 \pm 0.7$ days vs. $23.6 \pm 0.3$ days, Kaplan-Meier Survival Analysis Log-Rank $p<<0.05$ ).

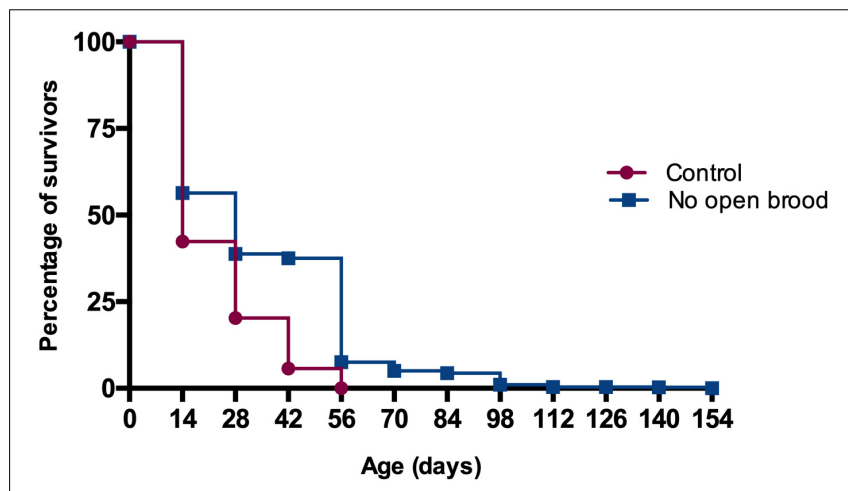

FIGURE 4 | Worker longevity is significantly higher in colonies with no open brood in comparison with control colonies (Kaplan-Meier Survival Analysis $\log -\operatorname{Rank} p<<0.05)$. groups and found a significant colony effect in each case (KaplanMeier Survival Analysis Log-Rank $p<<0.05$ ). Nevertheless, the range at which mean survival time in control colonies varied (19.7-26.9) was outside the range of mean survival in colonies with curtailed brood (31.0-39.3).

In both manipulated and natural colonies we observed large number of early losses of marked bees. Based on our observations, early deaths (noted at the first census) are due to the stress of handling and rejection by older workers in the recipient colonies. Early deaths in our data are in line with what was observed in introduced cohorts of bees in European honey bees in temperate regions (Mattila et al., 2001).

\section{Acini Size of HPGs in Different Bee Types}

As a reliable estimate of overall HPG size (Deseyn and Billen, 2005) acini diameter was measured for worker honey bees of different ages from control and treatment colonies. Acini diameter was significantly different across the bees of different age where 12-day-old nurses had the largest $(129.5 \pm 8.1 \mu \mathrm{m})$ and 21 day-old foragers had the smallest acini $(88.7 \pm 5.9 \mu \mathrm{m})$ (ANOVA, $p<<0.05$, Figure 5). Bees from treatment colonies exhibiting extreme longevity (65-75 days) had an intermediate acini size $(100.8 \pm 6.2 \mu \mathrm{m})$.

While the acini size for 12 day-old nurses was not different between the treatment and control colonies, there was a small but significant difference between the acini size of workers collected at the age of 21 and 45 days from manipulated and unmanipulated colonies. Note that there are no samples from control colonies after the 45-day time point because no workers survived to the next sampling day (65) in control colonies.

We explored the effect of colony environment on acini size via a nested ANOVA where colonies were nested within age groups and found that colony environment accounts for $14 \%$ of the total

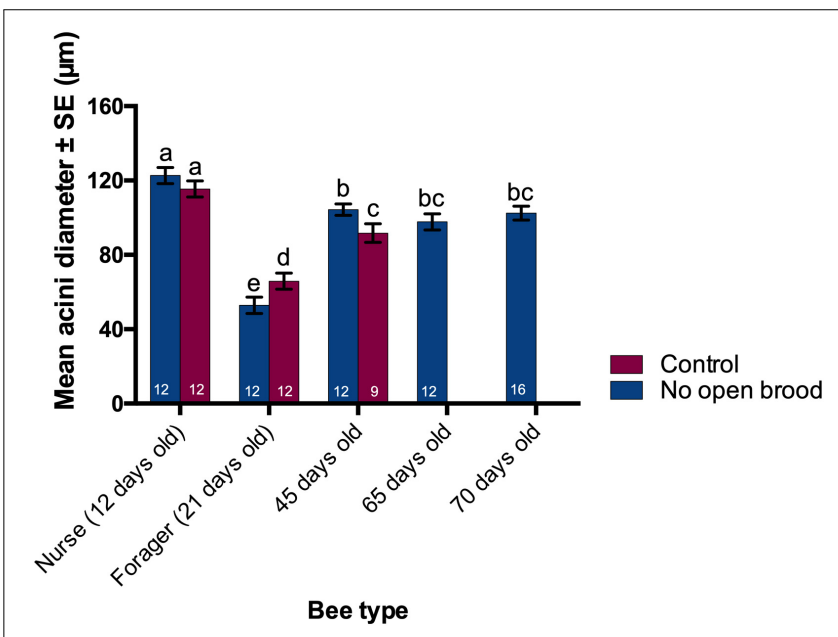

FIGURE 5 | Acini size of different bees collected at different times from treatment and control colonies. Hypopharyngeal gland acini size were significantly different between groups; largest in nurses, smallest in foragers, and intermediate in the long-lived winter-like bees (ANOVA, $p<<0.05$ ). Different letters denote significant differences in acini size between groups (Student's $t$-Test, $p<0.05$ ). 
variation observed while the remaining $86 \%$ can be attributed to brood status.

\section{DISCUSSION}

Here, we show increased longevity under typical seasonal conditions and upon brood manipulation in a tropical-adapted honey bee. Worker honey bees in temperate regions live up to 60 days in foraging season while a subpopulation of workers produced at the end of summer survive routinely more than 200 days through the winter (Fukuda and Sekiguchi, 1966; Southwick, 1991; Mattila et al., 2001). In this study, average worker longevity was significantly higher in the dearth season compared to when resources are ample. The direction of change in worker longevity was similar to reported for the honey bees in temperate regions, though less pronounced. By eliminating open brood, younger larvae that are fed by nurse bees and in cells that are not sealed with silk and wax, the gAHB workers were "winterized" and lived up to 5 months in spring and summer months.

One caveat of our study is that the longevity data collected in October came from worker bees harvested from a single colony and placed into two colonies upon marking them. Thus, all individuals involved are daughters of the same queen. However, naturally mated queen honey bees provide a large level of genetic variation because each queen mates with multiple drones (Kraus et al., 2005; Withrow and Tarpy, 2018). While not removing the influence of genetics on longevity, this approach provides a uniform genetic base instead of introducing various genetic make ups to the experimental design as an additional variable. Our results from the two independent colonies where open brood was eliminated via caging the queen and findings from earlier research in the temperate regions suggest that increased worker longevity in response to decreased brood is a general response in honey bees. In the future, experiments comparing various genetic backgrounds under brood-manipulated conditions as well as in different seasons could properly examine the interaction of genes with the signals for the seasonal change in worker longevity.

We also examined the HPGs of gAHBs. Size of HPG changes with the age and task of the bee in the hive, reflecting the behavioral status of the bee (Smodiš Škerl and Gregorc, 2015). Brood pheromone (BP) acts as a primer pheromone and facilitates the protein synthesis in the HPGs of workers (Brouwers, 1983; Huang and Otis, 1989; DeGrandi-Hoffman et al., 2010), which explains the largest HPG size of nurse bees. Interestingly, workers in winter have larger HPGs than summer foragers despite the lack of open brood (Moritz and Crailsheim, 1987; Hrassnigg and Crailsheim, 1998; Smodiš Škerl and Gregorc, 2015), suggesting a more complex effect of BP and interactions with brood on worker HPG size. The mean HPG size of the long-lived workers in gAHB colonies without open brood was larger than that of foragers and smaller than that of nurses as was previously shown for long-lived European honey bees in temperate regions (Fluri et al., 1982).

When taken together, the change in longevity and HPG size in the workers in colonies without open brood during floral abundance as in the March experiment, suggest that external seasonal conditions are indirectly communicated to the members through the change in the brood rearing capacity of the colony. Therefore, reduction in brood constitutes a signal for the existing workers to alter their biology in an adaptive manner in order to survive longer than usual through the dearth season. Previous studies in the temperate region show a gradual increase in the ratio of winter bees within the overall colony population corresponding to a gradual decrease in the brood rearing (Mattila et al., 2001; Mattila and Otis, 2007). This gradual change in proportion of long-lived bees implies the existence of a threshold effect where some workers respond to the brood signal earlier than the others. We have not examined systematically the change in brood production in PR honey bee colonies over the year. However, colony records for the amount of brood measured as combs with brood cataloged during the regular inspection of the hives by our field technician provides preliminary support. We present in Supplementary Material Appendix A records for 11 hives between February 2015 and January 2016 (number of hives were dictated by continuity). There was a significant effect of month of the year on the number of frames of brood $[F(17,179)=1.78, p<0.05]$, with the lowest brood levels between the months of August and January (4.45 \pm 0.12 frames), and highest between the months of February and July $(5,47 \pm 0.19$ frames. These periods correspond, respectively, to presence of scarce versus abundant forage (Little et al., 1977 and Figure 1). Additional ambient cues such as daily cycles in temperature, light, humidity may be functioning as predictive zeitgebers alongside the brood signal (Frisch and Aschoff, 1987; Giannoni-Guzman et al., 2014; Moore, 2016). Nevertheless, the fact that simply removing open brood in gAHB colonies in PR in spring affects the life-span of worker bees shows that brood availability is a key component of the signal for seasonal change in workers physiology.

In gAHB of PR the change in worker longevity in response to reduced open brood is similar to what was observed in overwintering $\mathrm{EHB}$ colonies in the temperate regions. The gAHBs are an introduction from an Africanized population that likely originally from Texas ca. 1994 (Acevedo et al., 2019). In general, AHBs are reportedly less successful than EHBs in overwintering (Villa and Rinderer, 1993). The leading hypothesis for this difference is that Africanized honey bees could be lacking in flexibility to produce longer-lived winter workers which is critical for keeping the colony population alive when brood is reduced (Southwick, 1991). However, African honey bees routinely survive broodless conditions as a part of their life cycle (McNally and Schneider, 1992). While European honey bees stop or severely limit brood rearing in at least part of the winter, African honey bees become broodless for 4 to 6 weeks during migration (Grozinger et al., 2014). Nevertheless, AHBs have exhibited limited success in expanding into temperate climates in spite of their remarkably rapid spread elsewhere (Kono et al., 2015; Lin et al., 2018) suggesting that flexibility in worker longevity is necessary but certainly not sufficient for honey bee colonies to survive through the temperate winter. Successful colonies must also act proactively to perceive the change in seasons and accumulate floral resources that will sustain them 
through dearth (Seeley and Visscher, 1985; Döke et al., 2015, 2018) unlike their tropical counterparts who still have access to a greatly reduced but still present number of flowering plants (Little et al., 1977). Moreover, colonies in temperate regions must successfully thermoregulate to keep the surface of the winter cluster above the cold-paralysis threshold of $10-12^{\circ} \mathrm{C}$ against extreme ambient temperatures (Seeley, 1989; Southwick, 1991; Döke et al., 2015). In case of gAHB in PR, there is evidence that this population has been under selection, likely to increase hoarding in expense of colony defense (Rivera-Marchand et al., 2012; Avalos et al., 2017). This could place the gAHB population at an advantage over other AHBs in the mainland for expansion further into the temperate zones.

Lack of open brood constituting a reliable signal for the shift in worker longevity in both temperate and tropical settings in both European and Africanized honey bees suggests the existence of conserved biochemical and neurological mechanisms to asses and react to seasonal change. These mechanisms could have been acquired in an earlier stage of honey bee evolutionary history, prior to radiating to colder parts of the globe. There may have been further selection on each of these traits at various levels in different populations where colonies are faced with specific stressors of temperate winters versus tropical dearth. Genomic comparisons between the bee stocks of tropics and temperate regions can provide valuable information on the parts of the genome under selection for specific stressors.

\section{DATA AVAILABILITY STATEMENT}

The raw data supporting the conclusions of this article will be made available by the authors, without undue reservation.

\section{REFERENCES}

Acevedo, J. P., Alberto, G., Cardona, G., Whitfield, C. W., Rodriguez, D. M., Uribe, J. L., et al. (2019). Colonization history and population differentiation of the Honey Bees (Apis mellifera L.) in Puerto Rico. Ecol. Evol. 9, 10895-10902. doi: 10.1002/ece3.5330

Amdam, G. V., Rueppell, O., Fondrk, M. K., Page, R. E., and Nelson, C. M. (2009). The nurse's load: early-life exposure to brood-rearing affects behavior and lifespan in honey bees (Apis mellifera). Exp. Gerontol. 44, 467-471. doi: 10.1016/j.exger.2009.02.013

Avalos, A., Pan, H., Li, C., Acevedo-Gonzalez, J. P., Rendon, G., Fields, C. J., et al. (2017). A soft selective sweep during rapid evolution of gentle behaviour in an Africanized honeybee. Nat. Commun. 8:1550. doi: 10.1038/s41467-017-018000

Brouwers, E. V. M. (1983). Activation of the hypopharyngeal glands of honeybees in Winter. J. Apic. Res. 22, 137-141. doi: 10.1080/00218839.1983.11100576

Cridland, J. M., Tsutsui, N. D., and Ramírez, S. R. (2017). The complex demographic history and evolutionary origin of the western honey bee, Apis Mellifera. Genome Biol. Evol. 9, 457-472. doi: 10.1093/gbe/evx009

DeGrandi-Hoffman, G., Chen, Y., Huang, E., and Huang, M. H. (2010). The effect of diet on protein concentration, hypopharyngeal gland development and virus load in worker honey bees (Apis mellifera L.). J. Insect Physiol. 56, 1184-1191. doi: 10.1016/j.jinsphys.2010.03.017

Deseyn, J., and Billen, J. (2005). Age-dependent morphology and ultrastructure of the hypopharyngeal gland of Apis mellifera workers (Hymenoptera, Apidae). Apidologie 36, 49-57. doi: 10.1051/apido:2004068

\section{AUTHOR CONTRIBUTIONS}

MD, CG, and TG designed and planned the study. MD, S-FC, and JA carried out the experiments. MD, S-FC, and JLA-R completed statistical analyses. MD, S-FC, JLA-R, CG, and TG prepared the manuscript for publication. All authors contributed to the article and approved the submitted version.

\section{FUNDING}

We acknowledge funding from Puerto Rico Science, Technology and Research Trust (CRG 2020-0139), NSF (DEB 1940621, HRD 1736019), USDA-APHIS (APP-8159 and APP-11783) to TG and NSF (IIS 1633184) to JLA-R.

\section{ACKNOWLEDGMENTS}

We thank Dr. Arián Avalos for constructive feedback on this manuscript and our field technician Tilden Aponte for the work on managing the honey bee colonies. We are especially grateful to the genetics technician Norma Rodríguez for supplying us materials for the honeybee collections. We would also like to thank José Fontánez for the access to the microscope used for HPG measurements and the necessary training for its use. Luz A. Sanchez Lopez and Michael de Jesus Soto helped with HPG dissections. Finally, we want to thank Isada Claudio Ford and Claudia Sofia Cordero for helping us with the paint-mark the 1-dayold bees.

Döke, M. A., Frazier, M., and Grozinger, C. M. (2015). Overwintering honey bees: biology and management. Curr. Opin. Insect Sci. 10, 185-193. doi: 10.1016/j. cois.2015.05.014

Döke, M. A., McGrady, C. M., Otieno, M., Grozinger, C. M., and Frazier, M. (2018). Colony size, rather than geographic origin of stocks, predicts overwintering success in honey bees (Hymenoptera: Apidae) in the Northeastern United States. J. Econ. Entomol. 112, 525-533. doi: 10.1093/jee/toy377

Eishchen, F. A., Rothenbuhler, W. C., and Kulinčević, J. M. (1982). Length of life and dry weight of worker honeybees reared in colonies with different workerlarva ratios. J. Apic. Res. 21, 19-25. doi: 10.1080/00218839.1982.11100511

Fluri, P., Lüscher, M., Wille, H., and Gerig, L. (1982). Changes in weight of the pharyngeal gland and haemolymph titres of juvenile hormone, protein and vitellogenin in worker honey bees. J. Insect Physiol. 28, 61-68. doi: 10.1016/ 0022-1910(82)90023-3

Frisch, B., and Aschoff, J. (1987). Circadian rhythms in honeybees: entrainment by feeding cycles. Physiol. Entomol. 12, 41-49. doi: 10.1111/j.1365-3032.1987. tb00722.x

Fukuda, H., and Sekiguchi, K. (1966). Seasonal change of the honeybee worker longevity in Sapporo, North Japan, with notes on some factors affecting the life-span. Jpn. J. Ecol. 16, 206-212.

Galindo-Cardona, A., Acevedo-Gonzalez, J. P., Rivera-Marchand, B., and Giray, T. (2013). Genetic structure of the gentle Africanized honey bee population (gAHB) in Puerto Rico. BMC Genet. 14:65. doi: 10.1186/1471-215614-65

Giannoni-Guzman, M. A., Avalos, A., Perez, J. M., Loperena, E. J. O., Kayım, M., Medina, J. A., et al. (2014). Measuring individual locomotor rhythms in honey 
bees, paper wasps and other similar-sized insects. J. Exp. Biol. 217, 1307-1315. doi: $10.1242 /$ jeb.096180

Giray, T., Huang, Z. Y., Guzmán-Novoa, E., and Robinson, G. E. (1999). Physiological correlates of genetic variation for rate of behavioral development in the honeybee, Apis mellifera. Behav. Ecol. Sociobiol. 47, 17-28. doi: 10.1007/ s002650050645

Goel, N., Banks, S., Mignot, E., and Dinges, D. F. (2009). PER3 polymorphism predicts cumulative sleep homeostatic but not neurobehavioral changes to chronic partial sleep deprivation. PLoS One 4:e5874. doi: 10.1371/journal.pone. 0005874

Grozinger, C. M., Richards, J., and Mattila, H. R. (2014). From molecules to societies: mechanisms regulating swarming behavior in honey bees (Apis spp.). Apidologie 45, 327-346. doi: 10.1007/s13592-013-0253-2

Grozinger, C. M., Sharabash, N. M., Whitfield, C. W., and Robinson, G. E. (2003). Pheromone-mediated gene expression in the honey bee brain. Proc. Natl. Acad. Sci. U.S.A. 100, 14519-14525. doi: 10.1073/pnas.2335884100

Harbo, J. R. (1993). Effect of brood rearing on honey consumption and the survival of worker honey bees. J. Apic. Res. 32, 11-17. doi: 10.1080/00218839.1993. 11101282

Hrassnigg, N., and Crailsheim, K. (1998). Adaptation of hypopharyngeal gland development to the brood status of honeybee (Apis mellifera L.) colonies. J. Insect Physiol. 44, 929-939. doi: 10.1016/S0022-1910(98)00058-4

Huang, Z. Y., and Otis, G. W. (1989). Factors determining hypopharyngeal gland activity of worker honey bees (Apis mellifera L.). Insectes Sociaux 36, 264-276. doi: 10.1007/BF02224880

Jeffree, E. P. (1951). A photographic presentation of estimated numbers of honeybees (Apis Mellifera L.) On Combs in $14 \times 81 / 2$ Inch Frames. Bee World 32, 89-91. doi: 10.1080/0005772x.1951.11094703

Kevan, P. G. (2007). Bees: Biology and Management. Enviroquest.

Kono, Y., Kohn, J. R., and Wicker-Thomas, C. (2015). Range and frequency of africanized honey bees in California (USA). PLoS One 10:e137407. doi: 10. 1371/journal.pone.0137407

Kraus, F. B., Neumann, P., and Moritz, R. F. A. (2005). Genetic variance of mating frequency in the honeybee (Apis mellifera L.). Insectes Sociaux 52, 1-5. doi: 10.1007/s00040-004-0766-9

Le Conte, Y., Mohammedi, A., and Robinson, G. E. (2001). Primer effects of a brood pheromone on honeybee behavioural development. Proc. R. Soc. B Biol. Sci. 268, 163-168. doi: 10.1098/rspb.2000.1345

Lin, W., McBroome, J., Rehman, M., and Johnson, B. R. (2018). Africanized bees extend their distribution in California. PLoS One 13:e0190604. doi: 10.1371/ journal.pone.0190604

Little, E. L., Wadsworth, F. H., and Marrero, J. (1977). Arboles Comunes de Puerto Rico y las Islas Virgenes (First). Available online at: http://edicionesdigitales.info/ biblioteca/arbolesprvilesp.pdf (accessed January 5, 2020).

Mattila, H. R., Harris, J. L., and Otis, G. W. (2001). Timing of production of winter bees in honey bee (Apis mellifera) colonies. Insectes Sociaux 48, 88-93. doi: 10.1007/PL00001764

Mattila, H. R., and Otis, G. W. (2007). Dwindling pollen resources trigger the transition to broodless populations of long-lived honeybees each autumn. Ecol. Entomol. 32, 496-505. doi: 10.1111/j.1365-2311.2007.00904.x

Maurizio, A. (1950). The influence of pollen feeding and brood rearing on the length of life and physiological condition of the honey bee. Bee World 31, 9-12.

Maurizio, A. (1954). Pollenernahrung und ILcbrnsvorgange bei der Honigbiene. Landw. Jb. Schweiz. 68, 115-182.

McLellan, A. (1978). Growth and decline of honeybee colonies and interrelationships of adult bees, brood, honey and pollen. J. Appl. Ecol. 15, 155-161.

McNally, L. C., and Schneider, S. S. (1992). Seasonal cycles of growth, development and movement of the African honey bee, Apis mellifera scutettata, in Africa. Insectes Sociaux 39, 167-179. doi: 10.1007/BF01249292

Moore, D. (2016). Honey bee circadian clocks: behavioral control from individual workers to whole-colony rhythms. J. Insect Physiol.? 47, 843-857. doi: 10.1016/ S0022-1910(01)00057-9
Moritz, B., and Crailsheim, K. (1987). Physiology of protein digestion in the midgut of the honeybee (Apis mellifera L.). J. Insect Physiol. 33, 923-931. doi: 10.1016/ 0022-1910(87)90004-7

Omholt, S. W. (1988). Relationships between worker longevity and the intracolonial population dynamics of the honeybee. J. Theor. Biol. 130, 275-284. doi: 10.1016/S0022-5193(88)80030-4

Pinto, M. A., Sheppard, W. S., Johnston, J. S., Rubink, W. L., Coulson, R. N., Schiff, N. M., et al. (2007). Honey bees (Hymenoptera: Apidae) of African origin exist in non-Africanized areas of the Southern United States: evidence from mitochondrial DNA. Ann. Entomol. Soc. Am. 100, 289-295.

Renzi, M. T., Rodríguez-Gasol, N., Medrzycki, P., Porrini, C., Martini, A., Burgio, G., et al. (2016). Combined effect of pollen quality and thiamethoxam on hypopharyngeal gland development and protein content in Apis mellifera. Apidologie 47, 779-788. doi: 10.1007/s13592-016-0435-9

Rivera-Marchand, B., Giray, T., and Guzman-Novoa, E. (2008). The cost of defense in social insects: insights from the honey bee. Entomol. Exp. Appl. 129, 1-10.

Rivera-Marchand, B., Oskay, D., and Giray, T. (2012). Gentle Africanized bees on an oceanic island. Evol. Appl. 5, 746-756. doi: 10.1111/j.1752-4571.2012. 00252.x

Seeley, T. D. (1989). The honey bee colony as a superorganism. Am. Sci. 77, 546-553.

Seeley, T. D., and Visscher, P. K. (1985). Survival of honeybees in cold climates: the critical timing of colony growth and reproduction. Ecol. Entomol. 10, 81-88. doi: 10.1111/j.1365-2311.1985.tb00537.x

Shechtman, O. (2013). "The coefficient of variation as an index of measurement reliability," in Methods of Clinical Epidemiology, eds S. A. R. Doi and G. M. Williams (Berlin: Springer), 39-49. doi: 10.1007/978-3-642-37131-8_4

Smedal, B., Brynem, M., Kreibich, C. D., and Amdam, G. V. (2009). Brood pheromone suppresses physiology of extreme longevity in honeybees (Apis mellifera). J. Exp. Biol. 212(Pt 23), 3795-3801. doi: 10.1242/jeb.035063

Smodiš Škerl, M. I., and Gregorc, A. (2015). Characteristics of hypopharyngeal glands in honeybees (Apis mellifera carnica) from a nurse colony. Slov. Vet. Res. 52, 67-74.

Southwick, E. E. (1991). “Overwintering in honey bees: implications for apiculture,” in Insects at Low Temperature, eds R. E. Lee and D. L. Denlinger (Boston, MA: Springer).

Stabentheiner, A., Pressl, H., Papst, T., Hrassnigg, N., and Crailsheim, K. (2003). Endothermic heat production in honeybee winter clusters. J. Exp. Biol. 206, 353-358. doi: 10.1242/jeb.00082

Vannette, R. L., Mohamed, A., and Johnson, B. R. (2015). Forager bees (Apis mellifera) highly express immune and detoxification genes in tissues associated with nectar processing. Sci. Rep. 5:1622. doi: 10.1038/srep16224

Villa, J. D., and Rinderer, T. E. (1993). Cold room thermoregulation, store consumption, and survival of Africanized and European honey bees (Apis mellifera L). Apidologie 24, 411-423. doi: 10.1051/apido:19930408

Winston, M. L., Taylor, O. R., Otis, G. W., Winston, M. L., Taylor, O. R., Otis, G. W., et al. (2016). Some differences between temperate european and tropical African and South American Honeybees. Bee World 64, 12-21. doi: 10.1080/0005772X. 1983.11097902

Withrow, J. M., and Tarpy, D. R. (2018). Cryptic "royal" subfamilies in honey bee (Apis mellifera) colonies. PLoS One 13:e0199124. doi: 10.1371/journal.pone. 0199124

Conflict of Interest: The authors declare that the research was conducted in the absence of any commercial or financial relationships that could be construed as a potential conflict of interest.

Copyright (c) 2020 Feliciano-Cardona, Döke, Aleman, Agosto-Rivera, Grozinger and Giray. This is an open-access article distributed under the terms of the Creative Commons Attribution License (CC BY). The use, distribution or reproduction in other forums is permitted, provided the original author(s) and the copyright owner(s) are credited and that the original publication in this journal is cited, in accordance with accepted academic practice. No use, distribution or reproduction is permitted which does not comply with these terms. 